\title{
ALIMENTAÇÃO INDÍGENA NA AMÉRICA LATINA: COMIDA INVISÍVEL, COMIDA DE POBRES OU PATRIMÔNIO CULINÁRIO? ${ }^{1}$
}

\author{
ESTHER KATZ ${ }^{2}$ \\ $I R D / C D S-U n B$
}

\begin{abstract}
RESUMO: Em todos os países latino-americanos, o modo de perceber a alimentação indígena é diferente, sendo em alguns casos simplesmente ignorada ou desconhecida. Às vezes, elementos dessa comida foram integrados ao modelo alimentar nacional. Em países como México e Peru, esses aspectos foram valorizados, mas, ao mesmo tempo, a comida dos índios de hoje é desvalorizada. Com estudos de caso no México (região mixteca, Estado de Oaxaca) e na Amazônia brasileira (Rio Negro, Amazonas), analisaremos como as dietas indígenas dessas regiões são percebidas sob duas perspectivas, de fora e de dentro. A partir do exame de suas características, será possível entrever que mesmo quando os índios vivem em situações desfavorecidas (no caso dos mixtecos), essas dietas são baseadas em um uso amplo e diverso dos recursos naturais, assim como de técnicas complexas de transformação dos alimentos. A partir dessa análise, discutiremos então se essas dietas podem ser consideradas como patrimônio culinário.
\end{abstract}

PALAVRAS CHAVE: Indígenas; alimentação; patrimônio.

ABSTRACT: In each Latin American country, indigenous food is perceived in a different way. In some cases, it is merely ignored. Sometimes, indigenous food elements have been integrated in the national food model. In countries like Mexico or Peru, these aspects have been valued, yet, at the same time, the food of present-day Indians is despised. With case studies from Mexico (the Mixtec highlands in the State of Oaxaca) and the Brazilian Amazon (Rio Negro, State of Amazonas), we will analyze how the indigenous diets of these regions are perceived, through two points of view, from inside and from outside. The study of their characteristics shows that even though Indians live in precarious situations (like the case of the Mixtecs), their diets are based on a wide and diverse use of the natural resources, as well as complex techniques of food processing. This analysis will lead us to discuss whether these diets may be considered as a culinary heritage.

KEYWORDS: Indians; food; heritage.

\footnotetext{
${ }^{1}$ Trabalho apresentado na 26. ${ }^{\text {a }}$ Reunião Brasileira de Antropologia, realizada entre os dias 01 e 04 de junho, Porto Seguro, Bahia, Brasil.

${ }^{2}$ Esther Katz possui doutorado em Antropologia pela Universidade de Paris-X (França). É pesquisadora do Institut de Recherche pour le Développement (IRD), associada ao Centro de Desenvolvimento Sustentável da Universidade de Brasilia (CDS-UnB). Tem experiência na área de Antropologia, com ênfase em Etnobotânica, atuando principalmente nos seguintes temas: etnobotânica, alimentação, agricultura, etnometeorologia, identidade cultural. Fora do Brasil, tem experiência de campo no México, na Indonesia, no Laos, no Congo e na Europa. E-mail: katz@mnhn.fr .
}

Espaço Ameríndio, Porto Alegre, v. 3, n. 1, p. 25-41, jan./jun. 2009. 
ESTHER KATZ - Alimentação indígena na América Latina ...

Como percebe-se a alimentação indígena nos países latinoamericanos? A situação dos indígenas varia muito de um país ao outro, e os sistemas alimentares dos indígenas são tão diversos como suas culturas. Em países onde uma proporção importante da população descende de indígenas, como México, Guatemala, Peru ou Bolívia, elementos dos sistemas alimentares indígenas foram integrados ao modelo alimentar nacional. Esses aspectos foram valorizados no contexto da construção da identidade nacional, mas, ao mesmo tempo, a comida dos índios atuais é desvalorizada. Para ilustrar esse tipo de situação, examinarei aqui o caso dos indios mixtecos, que vivem em uma das regiões mais desfavorecidas do México, no Estado de Oaxaca. Com base em pesquisas de campo realizadas ao longo de vinte anos, mostrarei quais são as particularidades da sua dieta e porque é considerada "comida de pobres". Em países com uma proporção pequena de população indígena, como Brasil ou Argentina, a alimentação dos indígenas tende a ser ignorada. No Brasil, a culinária nacional é mais européia, mas integrou, mais ou menos em cada região, elementos das culinárias indígenas e africanas. As dietas dos indígenas da Amazônia são desconhecidas e são invisíveis nos espaços públicos da região. Com base em pesquisas de campo realizadas nos últimos dois anos, examinarei as particularidades da alimentação dos indígenas de Santa Isabel do Rio Negro, uma pequena cidade multi-étnica do Médio Rio Negro, no Estado de Amazonas. Analisarei como as dietas indígenas nesses dois casos são percebidas sob duas perspectivas, de fora e de dentro. A partir dessa análise, discutirei a possibilidade de considerar essas dietas como patrimônio culinário.

\section{A alimentação dos mixtecos do México: comida de pobres}

Comecei os meus estudos de antropologia da alimentação em 1983 no México em um projeto que tratava dos problemas de saúde e nutrição dos mixtecos, um grupo indígena do Estado de Oaxaca ${ }^{3}$.

\footnotetext{
3 "Biología humana y desarrollo en la Mixteca Alta", projeto UNAM/CNRS dirigido por Luis Alberto Vargas e Philippe Lefèvre-Witier.
} 
ESTHER KATZ - Alimentação indígena na América Latina ...

Naquele momento, os serviços públicos estavam preocupados com a incidência da desnutrição em toda uma parte da população, sobre tudo nas chamadas "zonas marginalizadas"4. No início da minha estadia na região, visitei a sede local do Instituto Nacional Indigenista, onde uma mulher jovem, responsável pelo setor de nutrição, afirmava que "os indígenas não sabem o que devem comer". Ela mesma era da região e tinha um tipo físico indígena, mas não se considerava como tal. No México, oficialmente, apenas os locutores de línguas indígenas são reconhecidos como indígenas, mas uma grande parte da população do centro e do sul do país são descendentes de indígenas e conserva traços culturais indígenas, em particular na alimentação. Ademais, as fronteiras étnicas são totalmente flutuantes e fluidas. Atualmente, os últimos censos incluem também como "indígenas" as pessoas que vivem em um lar onde um membro fala uma língua indígena (INEGI, 2007) ${ }^{5}$.

O México é um país com fortes raízes indígenas. A mestiçagem aconteceu sobre tudo entre homens espanhóis e mulheres indígenas que transmitiram a sua culinária e os seus hábitos alimentares. Os espanhóis, no início da colonização, adotaram rapidamente hábitos alimentares indígenas, como o consumo da tortilla de milho (ALBERRO, 1992). Depois da independência do país, em 1821, a população já não era dividida entre brancos, negros, índios e diferentes tipos de "mestiços", mas apenas entre índios e "mestiços", ou seja, os espanhóis tornaram-se "mestiços". As elites foram atraídas por modelos de consumo europeu, mas finalmente a culinária nacional foi construída em base nas culinárias regionais, derivadas em grande parte dos hábitos

\footnotetext{
${ }^{4} \mathrm{Na}$ época colonial, os espanhóis apropriaram-se das melhores terras, e deixaram aos indígenas as terras pendentes das montanhas. Assim os indígenas ficaram vivendo nas "regiões de refugio", como as chamou o antropólogo mexicano Gonzalo Aguirre Beltran (1967). Os poderes públicos da segunda parte do século XX designaram-nas "zonas marginalizadas", zonas à margem do desenvolvimento do país.

${ }^{5}$ Assim em 2005, 423.000 pessoas falavam mixteco, uma língua otomangue, mas 651000 moravam em um lar com membros locutores de mixteco (INEGI, 2007). Pelos censos, o número de locutores de línguas indígenas estava crescendo de jeito análogo ao resto da população, mas entre 2000 e 2005 ficou estável e, para alguns grupos, baixou. Isso indica que a prática das línguas indígenas esta baixando entre os mais jovens. Também, desde o movimento zapatista, mais pessoas consideram-se indígenas ainda quando já não falam uma língua indígena. No caso da região mixteca, em 1890, 90\% da população era indígena (PASTOR, 1987). Em 2005, no estado de Oaxaca, apenas 35\% da população falava uma língua indígena (INEGI, 2007). Toda uma parte das comunidades indígenas, sobre tudo na Mixteca Baixa (ao noroeste), deixou de falar a sua língua ao início do século XX (PASTOR, 1987), mas compartem a mesma cultura. Outras comunidades, como San Pedro Yosotato, onde desenvolvi a pesquisa, estão em processo de abandono da língua mixteca. Nesse povoado, que tem uma pequena proporção de moradores "mestiços", deixaram de falar mixteco às crianças nos anos sessenta.
}

Espaço Ameríndio, Porto Alegre, v. 3, n. 1, p. 25-41, jan./jun. 2009. 
ESTHER KATZ - Alimentação indígena na América Latina ...

alimentares indígenas (BAK-GELLER, 2008). No México, a tortilla de milho, os feijões e a pimenta são o denominador comum da alimentação nacional (KATZ, 2004). Esses três elementos básicos transpassam as épocas e as classes sociais. Entre os camponeses ou as classes baixas urbanas, os feijões são o prato principal da refeição. Nas classes sociais com mais recursos econômicos, os feijões acompanham um prato de carne.

No México, existem muitos tipos de desigualdade. Em primeiro lugar, tem uma grande desigualdade no desenvolvimento do país, com setores avançados como as grandes cidades e agricultura no norte do país e outros com poucos serviços (falta de estradas, de transporte, de energia, de saneamento básico, de serviços médicos). Esses setores, chamados "zonas marginalizadas", estão principalmente nas zonas montanhosas do sul e sudeste (como a região mixteca), onde se encontra uma forte proporção de população indígena. Geralmente, nessas regiões, o acesso às terras cultiváveis é limitado, o que é a causa de muitos conflitos inter e intra-comunidades.

Em segundo lugar, em nível regional, como no caso da Mixteca, tem muitas diferenças em recursos naturais, sobretudo entre zonas semi-áridas e zonas úmidas. As áreas que foram extremamente exploradas pelos espanhóis na época colonial (extração de madeira usada na construção das cidades, introdução de cabras) são atualmente as mais pobres. Cada comunidade pode ser mais ou menos pobre, em relação ao acesso aos serviços, à terra e aos recursos naturais. A emigração é muito forte nas Mixtecas Alta e Baixa há várias décadas, e é mais recente na parte sul, mais tropical, a Mixteca da Costa.

Em terceiro lugar, dentro das comunidades, também pode encontrar-se uma desigualdade entre famílias, geralmente em relação ao acesso às terras, mas recentemente em relação ao número de membros emigrados aos Estados Unidos que enviam remessas (KATZ, 2008).

As diferenças no consumo alimentar dependem muito desses fatores de desigualdade. No caso das Mixtecas Alta e Baixa, muitas comunidades dedicam-se aos cultivos de auto-subsistência, mas só têm auto-suficiência entre um e seis meses. Desde varias décadas, para poder comprar milho e feijão durante o resto do ano, os agricultores 
ESTHER KATZ - Alimentação indígena na América Latina ...

trabalham freqüentemente fora da comunidade por alguns meses ou anos. Conheci famílias que não tinham nem suficientes terras nem suficiente dinheiro para poder comer feijão em cada refeição, assim consumiam apenas tortillas com sal. Alem disso, os recursos são sazonais. Há folhas comestíveis e cogumelos na estação da chuva e frutas em alguns períodos, o que não impede a carência antes da maturação do milho. Nas zonas úmidas, quando chove muito, as estradas são intransitáveis e não chegam produtos de fora, e nos períodos muito secos, nada cresce (CASAS et al, 1987). Nos anos oitenta, a maioria das famílias comia carne eventualmente, mais ou menos uma vez a cada duas semanas; o consumo de carne era o que marcava a diferença entre as famílias mais ricas e as outras (CASAS et al, 1987) ${ }^{6}$. Um dia, um mixteco me comentou: "os cachorros dos gringos comem melhor que nós", é dizer, esses cachorros comem carne todos os dias. Os mixtecos têm mais confiança em alimentos vegetais do que animais, mas a carne é um alimento de prestígio consumido, sobretudo nas festas, em forma de caldo, tamales (um tipo de pamonha), mole (molho denso de pimenta) ou barbacoa (forno subterrâneo). Esses pratos são consumidos também em todo o México.

Antes de tudo, uma grande parte dos indígenas é pobre, vêem-se como pobres e são vistos como pobres. Em algumas comunidades da Mixteca Baixa, os moradores chamam-se ñu la'vi, "os pobres" em lugar de $\tilde{n} u$ savi, "os mixtecos", "o povo da chuva" (Alejandro de Avila comunicação pessoal, 1987).

Muitas pessoas no país têm a idéia de que os indígenas são "ignorantes", "atrasados" e resistem ao progresso. Por várias décadas, o Instituto Nacional Indigenista planejou "a integração dos indígenas à nação", embora muitos deles considerem-se como "os autênticos mexicanos". Outra idéia comum era de que a comida indígena não era nutritiva, que a tortilla não era tão nutritiva como o pão de trigo e que não fornecia suficiente força para trabalhar (BERTRAN, 2005).

$\mathrm{Na}$ realidade, o quê comem os indígenas? Como todos os mexicanos, eles comem tortilla, feijão e pimenta. Isso é a sua comida diária. Em cada região, as tortillas são mais ou menos grandes, mais ou

\footnotetext{
${ }^{6} \mathrm{Na}$ época da conquista espanhola, já havia uma diferença social e econômica entre nobres e camponeses. Os nobres mixtecos consumiam carne, sobre tudo de caça; os camponeses não tinham direito de caçar e comiam apenas pequenos animais (KATZ, 2006b).
} 
ESTHER KATZ - Alimentação indígena na América Latina ...

menos grossas e de cores diferentes, feitas com milho branco, amarelo, vermelho ou azul. A pimenta é acomodada de diferentes maneiras, crua (inteira ou em fatias) ou em molho: crua e cortada em pedaços com tomate, cebola e folha de coentro, cozida ou assada, e pilada com outros ingredientes. Em cada região existem diferentes tipos de molhos, geralmente verdes ou vermelhos. Os mixtecos preparam tortillas grandes e molhos feitos de pimenta seca assada. Uma especialidade das culinárias mixteca e zapoteca ${ }^{7}$ é o mole amarillo, um molho denso de pimenta (com massa de milho branco) de cor laranja ("amarela").

Para os mixtecos, uma refeição considerada apropriada é composta de um prato com caldo (geralmente um caldo de feijão), tortillas e pimenta, crua ou em molho. Também se pode comer um caldo de quelites (folhas), que pode substituir os feijões, ou um caldo de carne, ou ainda os ovos. Quando viajam ou vão à roça, levam um taco (tortilla recheada com feijão e pimenta ou quelites ou às vezes carne) (KATZ, 2006a).

Os quelites são uma das características da comida dos indígenas, ou pelo menos de todos os camponeses descendentes de indígenas. Esta categoria não tem um equivalente exato em espanhol, assim o nome nahuatl quilit/ foi adaptado ao espanhol como quelite. Designa as folhas novas de ervas, cipós ou arbustos que se comem cruas ou cozidas. Muitas dessas plantas são o "mato" das roças de milho ou das hortas de café. Também crescem ao lado dos caminhos ou na floresta, ou às vezes são cultivadas. Coletam-se quando se limpa as roças, no curso do trabalho ou do caminho, o que não pede um trabalho ou um esforço particular. Por isso os quelites são considerados como comida de pobres. Nas pesquisas do Instituto Nacional de Nutrição dos anos setenta, que foram executadas por questionários, esses alimentos não apareceram porque os camponeses que os consumiam tinham vergonha de mencioná-los. Os camponeses de tradição indígena comem também muitas espécies de flores, cultivadas ou silvestres, que para vários grupos, entram na mesma categoria dos quelites (KATZ, 1992).

Os cogumelos são uma particularidade da alimentação indígena. Em varias regiões, os mestiços os comem também, mas não têm o

\footnotetext{
${ }^{7}$ Os zapotecos, vizinhos dos mixtecos e também de língua otomangue, ocupam a parte leste do Estado de Oaxaca.
}

Espaço Ameríndio, Porto Alegre, v. 3, n. 1, p. 25-41, jan./jun. 2009. 
ESTHER KATZ - Alimentação indígena na América Latina ...

conhecimento para sua colheita. Não sabem distinguir os comestíveis dos venenosos e não sabem onde achá-los.

Os indígenas comem ocasionalmente alguns animais de caça. Em muitas regiões, o meio ambiente é degradado. A caça é uma atividade menor e nem todos sabem caçar. Consomem mais animais pequenos (esquilos, pássaros, tatus, sarigueias, coatis, etc.). Vários animais são consumidos também como medicina e o veado ainda tem um papel simbólico (KATZ, 2006b). Entre os animais, os que os indígenas comem mais são os insetos (que para eles não constituem uma categoria separada): gafanhotos, formigas, lagartas, larvas de escaravelhos e vespas, e percevejos (esses últimos, comidos vivos).

Os indígenas consomem muito pouco leite (já que não o podem digerir) e poucos laticínios. Não sabem fazer queijo e não dominam as técnicas (árabo-andaluzes) de doçaria que, na época colonial, foram do domínio das freiras (ZOLLA, 1988).

Com as mudanças econômicas e sociais dos últimos anos, devido à emigração aos Estados Unidos, os mixtecos já não comem tantos quelites, que representam a comida dos pobres. A carne e os produtos industriais são mais consumidos do que antes, já que o dinheiro das remessas chega aos povoados. Esse dinheiro permite também o consumo no cotidiano de alimentos festivos como tamales e moles. Entretanto, os mixtecos seguem consumindo cogumelos e insetos (e carne de caça quando podem), alimentos tipicamente indígenas, mas sempre muito apreciados (KATZ, 2008).

\section{A alimentação dos indígenas do Rio Negro: comida invisível}

No Brasil, uma grande parte da população vive nas áreas costeiras e no sul do país, não tendo raízes indígenas. Boa parte dessa população nunca se encontra com os indígenas e percebe-os como exóticos, desconhecendo totalmente seu modo de vida. Desconhece, também, a Amazônia e seus recursos alimentares, fora o peixe e a farinha. Ademais, existem discursos, entre os quais discursos científicos, sobre o fraco valor nutricional da mandioca (DUFOUR, 1991). Apenas alguns pratos da culinária paraense adquiriram fama, como o pato no tucupi ou 
ESTHER KATZ - Alimentação indígena na América Latina ...

o tacacá (DE ROBERT e VAN VELTHEM, 2008). Há quinze anos ainda não se conhecia, fora da Amazônia, o cupuaçu ou o açaí que, agora, se consome em todo o Brasil, na forma de sorvetes, sucos ou vinhos. Em regiões da Amazônia, como o Acre, uma grande parte da população é oriunda do Nordeste e desconhece os costumes dos indígenas da região. De igual maneira, essa população não sabe o que os indígenas comem. Em outras partes da Amazônia, como no Amazonas, uma grande parte da população descende de índios, mas não se percebe como indígena. A população do Médio Rio Negro era considerada cabocla (OLIVEIRA, 1972), mas nos últimos anos ressurgiram as identidades indígenas, que passaram a ser mais valorizadas.

Santa Isabel do Rio Negro, onde comecei um trabalho de campo em $2007^{8}$, é uma pequena cidade multi-étnica de 7500 habitantes. Os mais antigos moradores são os baré, um grupo indígena arawak que perdeu sua língua a favor da língua geral (o nheengatu) e, assim, foram facilmente considerados caboclos ${ }^{9}$. Muitos moradores são do grupo tukano oriental (tukano, pira-tapuya, desâna, tuyuka, etc.) e alguns são baniwa (arawak). Eles chegaram do Alto Rio Negro ao longo de vários períodos, já no "tempo da borracha" para coletar produtos florestais, e recentemente para encontrar terras de cultivo ou acessar serviços escolares ou de saúde; muitos se estabeleceram primeiro em pequenas comunidades ao lado do rio antes de se mudarem a Santa Isabel (CALBAZAR e RICARDO, 2006). Nem todos conservaram a prática de uma língua indígena, e entre os grupos tukano, a língua tukano tende a se tornar língua franca, ainda que tradicionalmente esses indígenas sejam multilíngües (RENAULT-LESCURE, 1991). Os yanomami do Rio Marauia, um afluente do Rio Negro, vêm para a cidade procurando serviços urbanos (saúde, escola, aposentadoria), fazer compras e vender artesanato. Isso acontece também com os kamã e nadebe (grupos maku) da região. Na cidade, moram também descendentes de comerciantes portugueses, que por várias décadas foram compradores de produtos florestais, e em vários casos, têm avós indígenas. Já, os

\footnotetext{
8 Projeto PACTA (Populações, Agrobiodiversidade e Conhecimentos Tradicionais Associados na Amazônia), convênio CNPq-Unicamp/IRD-UR 169, n 492693/2004-8, dirigido por Mauro Almeida (Unicamp) e Laure Emperaire (IRD), financiamento CNPq, IRD, ANR-Biodivalloc e BRG, com a participação da ACIMRN (Associação das Comunidades Indígenas do Médio Rio Negro). Autorização n ${ }^{\circ}$ 139 publicada no DOU (14/04/2006).

${ }^{9}$ Atualmente, também, pessoas com pais ou avôs de diferentes origens se consideram baré.
} 
ESTHER KATZ - Alimentação indígena na América Latina ...

nordestinos (geralmente homens) chegaram mais recentemente e se casaram com mulheres indígenas ou caboclas. Algumas pessoas de fora (como de Manaus) são empregadas da prefeitura ou dos salesianos que administram o hospital e uma escola.

Chegando a Santa Isabel, percebe-se pouco da alimentação indígena. Vendem-se muito poucos produtos locais nas lojas, mais especializadas em produtos (alimentares e outros) trazidos de Manaus por barco: oferecem alimentos e bebidas industrializados, algumas verduras como tomate, cebola e alho, limão, charque e frango congelado. Os poucos alimentos locais vendidos, ocasionalmente, são: castanhas, cupuaçu, farinha, e raramente pimenta em pó. Os lugares (pequenos restaurantes ou lanchonetes) que oferecem refeições sugerem, no café da manhã, pão, manteiga e café; os que abrem ao meio-dia propõem uma refeição composta de peixe ou carne, arroz, feijão, farofa (e a farinha); e os da noite, churrasco, sanduíches, salgadinhos, pastéis e sucos. Nas festas comunitárias, serve-se carne com arroz, feijão e macarrão e pequenas bancas oferecem pudim, bolos, salgadinhos, churrasco e, às vezes, peixe assado. As cozinhas das casas da cidade são cheias de panelas de alumínio, panelas de pressão, frigideiras e pratos de vidro ou de plástico. Uma grande parte dos habitantes tem fogões a gás.

Onde está a comida indígena?

À primeira vista, está invisível. Para encontrá-la, é preciso ir às roças ao redor da cidade. Mas as roças também são invisíveis, ocultadas no meio da floresta (Laure Emperaire, comunicação pessoal, 2008). Duas ou três famílias de grandes comerciantes têm fazendas fora da cidade, com gado e grandes extensões de terra, ao contrário da agricultura de subsistência. As roças familiares de mandioca são pequenas, manejadas por mulheres, sobretudo mulheres que não têm emprego assalariado. Muitas são aposentadas. Nas roças, a mandioca é a planta principal, mas são cultivadas muitas espécies associadas (outros tubérculos, abacaxi, pimenta, caruru, etc.) e árvores frutíferas (EMPERAIRE et al, 2008). Na roça, encontra-se a casa de farinha, onde é transformada a mandioca brava (em farinha, beiju, etc.). Também, nela, 
ESTHER KATZ - Alimentação indígena na América Latina ...

são encontrados todos os utensílios tradicionais, sobretudo os de cestaria (tipitis, peneiras, etc.) ${ }^{10}$.

Os produtos derivados da mandioca brava constituem uma parte central da dieta indígena do Rio Negro e de uma grande parte da Amazônia (e são consumidos também em outras regiões do Brasil ${ }^{11}$ ). As técnicas de transformação são complexas, e implicam uma cadeia operacional longa. Nessa região, cultivam-se mais de setenta variedades dessa planta (EMPERAIRE et al, 2008) e os produtos derivados são muito diversos $^{12}$ : diferentes tipos de farinha, beiju, mingau, caxiri (cerveja), alem de tapioca, tucupi e maniçoba (folhas de maniva). A pimenta é um elemento importante da dieta. Na região, cultivam-se muitas variedades dessa planta. Prepara-se a pimenta em pó (jiquitaia), com ou sem sal, ou em arubé (macerada em suco de mandioca). Alguns produtos da roça nem chegam até as casas da cidade. Ao longo do dia de trabalho na roça, as pessoas comem tubérculos assados (inhame, cará, taioba, batata doce, macaxeira), e chupam cana de açúcar e frutas (ingá, caju, cupuaçu, abacaxi, etc.). Uma parte dos produtos (em particular as frutas) é levada para casa na cidade. Os produtos dos quais há um excedente são doados ou vendidos a uma rede de parentes e vizinhos. Quase nunca chegam às lojas, já que não existe uma tradição de mercados entre os indígenas da região. Um pequeno mercado de agricultores foi criado há pouco tempo para permitir a venda de excedentes agrícolas e produtos transformados, como beijus de mandioca, mas ainda é muito reduzido. Vendem-se frutas (como a pupunha), verduras (como a couve), vinho de açaí e de bacaba, e também pudim e bolos.

Tradicionalmente os produtos eram - e, no Alto Rio Negro, ainda são - trocados formalmente entre grupos vinculados por relações de aliança, em rituais chamados dabucuri em língua geral (REICHELDOLMATOFF, 1968; CHERNELA, 1993; RIBEIRO, 1995). Por exemplo, um grupo mais especializado na caça troca carne por peixe de outro grupo $^{13}$. Alem disso, celebra-se a coleta de cada tipo de fruta (ingá,

\footnotetext{
${ }^{10}$ No projeto PACTA, o estudo dos objetos é levado a cabo por Lucia Van Velthem.

11 Ver Embrapa (2005).

12 ver também Ribeiro (1995), sobre o Alto Rio Negro.

${ }^{13}$ Por exemplo, na Colômbia, os desâna considerados como caçadores trocavam carne por peixe dos tukano, pira-tapuya e wanano, mais especializados na pesca (REICHEL-DOLMATOFF, 1968).
} 
ESTHER KATZ - Alimentação indígena na América Latina ...

pupunha, etc.). Tanto recursos alimentares como objetos são trocados, já que alguns grupos são especializados na fabricação de certos objetos (ralos baniwa, cestos de carga maku, etc.) (RIBEIRO, 1995). A diversidade das plantas cultivadas na região também é o resultado de trocas (EMPERAIRE et al, 2008). As regras de exogamia dos tukano e dos arawak contribuíram, provavelmente, não só na circulação das plantas e dos produtos, mas também dos saberes culinários. Esses grupos sempre se casam fora de seu patriclã, e os tukano praticam ademais a exogamia lingüística (REICHEL-DOLMATOFF, 1968; HUGH-JONES, 1979; CHERNELA, 1993; RIBEIRO, 1995; GARNELO, 2007). No contexto urbano, mantêm-se as regras de exogamia, e acontecem mais uniões interétnicas, entre tukano, baré e baniwa, mas também com nordestinos e outros "brancos".

De modo geral, a maioria dos grupos sociais do Rio Negro (tukano, arawak e descendentes dos mesmos grupos) compartilham o mesmo sistema alimentar. As diferenças entre grupos étnicos são pequenas; existem na maneira de elaborar ou acomodar os pratos ${ }^{14}$. De uma aldeia a outra, os recursos naturais são diferentes e desiguais: os peixes são abundantes em algumas zonas e raros em outras, como nas cachoeiras; os gostos variam também: em algumas aldeias, come-se cogumelos ou lagartas, em outras não.

A comida básica do Rio Negro é um caldo apimentado com peixe, chamado na língua geral quinhãpira (de quinha, pimenta, e pira, peixe), acompanhado de beiju ou farinha de mandioca. No contexto urbano e atual, consome-se também alimentos da culinária nacional ("comida dos brancos"), como arroz, feijão e carne ${ }^{15}$. Arroz e feijão são consumidos junto com a farinha. Carne de boi ou de frango, fresca, congelada ou salgada, pode substituir o peixe. O peixe é consumido em caldo, assado, moqueado ou frito. Nas aldeias tukano e arawak do Alto Rio Negro, a quinhãpira é consumida com beiju, de manhã e no fim da tarde, e toda a comunidade come na casa comunitária e compartilha dos diferentes pratos $^{16}$. De manhã, come-se também mingau, em uma cuia passada de mão em mão ${ }^{17}$. As pessoas comem durante o dia aquilo que

\footnotetext{
${ }^{14}$ Cf. Luciano (2008) sobre as diferenças entre baniwa e tukano.

${ }^{15}$ Ver também Eloy (2008) sobre a cidade de São Gabriel da Cachoeira.

${ }^{16}$ Sobre os baniwa, cf. Luciano (2008).

${ }^{17} \mathrm{O}$ mingau é também a comida predileta dos bebês e dos velhos que já não têm dentes.
} 
ESTHER KATZ - Alimentação indígena na América Latina ...

encontram na roça ou no mato (tubérculos, frutas) e bebem chibé (água com farinha) em uma cuia, do mesmo jeito que o mingau. No Médio Rio Negro, as pessoas comem também no meio dia, se não estão nas roças. Os habitantes das comunidades compartilham também os seus pratos na casa comunitária, todos os dias ou apenas nos fins de semana. $\mathrm{Na}$ cidade, as refeições acontecem no lar, e são compartilhadas apenas nas festas. Atualmente, na cidade, o café e o pão são mais consumidos pela manhã do que o tradicional mingau. Entre as refeições, comem-se "merendas" com vinho de açaí ou bacaba com farinha ou tapioca, sucos de fruta, frutas, pão, bolacha. Antes, para preparar sucos, ralava-se ou pilava-se as frutas e depois filtrava-se em uma peneira. Agora se faz no liquidificador. Antes, nas festas, serviam-se tartarugas de rio, peixe moqueado, agora predomina a "comida dos brancos". Não havia festas sem caxiri, a cerveja de mandioca. Os missionários proibiram o consumo dessa bebida. Atualmente, poucas mulheres de Santa Isabel sabem fazê-lo e, em seu lugar, bebem-se bebidas industriais como cerveja ou cachaça.

Na região, os indígenas yanomami não participam dessas trocas e não se casam com os outros grupos ${ }^{18}$. Muitos moradores de Santa Isabel consideram que não são civilizados e acham que não comem mandioca, apenas mingau de banana da terra. Porem, os yanomami comem farinha, sobretudo quando viajam a Santa Isabel, mas a mandioca não é o alimento principal como para os outros povos do Rio Negro. A banana é efetivamente o alimento básico dos yanomami, embora antes tenha sido o milho. Além disso, os yanomami caçam muito e coletam muitas plantas silvestres (MILLIKEN et al, 1999). Eles afirmam não incorporar pimenta a seus $\operatorname{pratos}^{19}$ e não consomem caxiri. A comida dos yanomami é mais invisível ainda do que a dos outros grupos indígenas.

\section{Conclusão}

\footnotetext{
18 Mas no passado, capturavam mulheres nas expedições guerreiras.

${ }^{19}$ Em Roraima, Bruce Albert (comunicação pessoal, 2008) observou que os yanomami comem pimenta, mas a pimenta não é um elemento central da refeição e é consumida de maneira diferente das etnias do Rio Negro.
} 
ESTHER KATZ - Alimentação indígena na América Latina ...

Como conclusão, isso nos leva à questão inicial: pode-se considerar os sistemas alimentares dos indígenas do Rio Negro e o dos mixtecos do México, como patrimônio culinário?

Acho que devemos estabelecer primeiro uma diferença entre gastronomia e patrimônio culinário. As grandes gastronomias (francesa, chinesa, etc.) são o resultado de distinções sociais, de desigualdades. Foram cozinhas formadas a partir de cortes e elites que tinham acesso privilegiado aos recursos oriundos de diferentes regiões de um reino ou império, embora constituídas sobre bases das tradições culinárias locais ainda vigentes.

No caso da comida mexicana, a gastronomia nacional atual é o produto da culinária da Corte imperial asteca que se fundiu à culinária espanhola medieval (com influências árabes) e chegou a um ponto alto de refinamento na época colonial (GONZALEZ DE LA VARA, 1996-1997). Como vimos, essa culinária recebeu influências européias no século XIX e se construiu com receitas regionais. Atualmente a culinária nacional está em vias de patrimonialização. Um grupo de pessoas fez uma demanda de registro da culinária mexicana como "patrimônio imaterial" na Unesco. Não foi aceita até o momento, mas o processo de patrimonialização está em curso, quer seja reconhecido ou não pela Unesco (PETRICH, 2005).

Nesse ponto da minha pesquisa, chego às seguintes propostas: acho que essas duas culinárias indígenas regionais podem ser consideradas como patrimônio culinário, primeiro em relação a sua qualidade gustativa, embora seja subjetivo. Nos dois casos, essas culinárias abarcam o uso de recursos naturais animais e vegetais muito diversos (com mais diversidade animal na Amazônia, sobretudo peixes), os sistemas de exploração do meio ambiente são complexos, em particular os sistemas agrícolas. Tais sistemas se apóiam em uma planta chave (milho/mandioca) complementada por uma grande diversidade de outras plantas cultivadas. Os modos de transformação alimentar são também complexos, em particular das plantas chave. Alem disso, esses dois sistemas alimentares têm muito em comum com a alimentação das regiões vizinhas ${ }^{20}$, mas certas preparações e a combinação dos

\footnotetext{
${ }^{20}$ Similaridades entre pratos de diferentes regiões do México (comida mixteca e zapoteca, comida de Oaxaca e do Planalto Central, etc.); similaridades entre as diferentes zonas da Amazônia baseadas no consumo da mandioca e da pimenta (em particular a bacia do Amazonas e do Orenoco): ver Schoepf
} 
ESTHER KATZ - Alimentação indígena na América Latina ...

elementos da culinária são particulares. Sugiro incluir também critérios que geralmente não entram na constituição dos produtos culinários típicos: a riqueza simbólica dos alimentos, desde a sua exploração no meio ambiente até o seu consumo, os mitos relacionados, as relações sociais ao redor da alimentação e as "maneiras à mesa". Entre os mixtecos, poucos mitos de origem das plantas ainda são conhecidos, mas representações simbólicas profundas da alimentação persistem até hoje, relacionando o meio ambiente (a montanha, o clima) com os processos reprodutivos e a fertilidade (KATZ, 2006c). Entre os grupos étnicos do Rio Negro, a mitologia ainda é muito presente, pelo menos nas aldeias, e a alimentação está relacionada também com os processos reprodutivos e a fertilidade (REICHEL-DOLMATOFF, 1968; HUGH-JONES, 1979). Ademais, existem sistemas de prescrições e proibições alimentares muito complexos e de uma grande riqueza simbólica (BUCHILLET, 1988; GARNELO, 2007). Os modos de servir a comida são próprios da cultura e também relacionados a uma simbologia. Falta investigar mais profundamente a respeito de esses critérios.

\section{Referências bibliográficas}

AGUIRRE BELTRÁN, Gonzalo. Regiones de Refugio: el desarrollo de la comunidad y el processo dominical en Mestizo América. Cidade do México: Instituto Indigenista Interamericano. 1967.

ALBERRO, Solange. Del gachupín al criollo: o de cómo los españoles de México dejaron de serlo. Cidade do México: El Colegio de México, 1992.

BAK-GELLER, Sarah. Les livres de recettes «francisés» au Mexique au XIX ème siècle: la construction de la nation et d'un modèle culinaire national. Anthropology of Food, Sallebœuf (France), n. 4, mai. 2008. Disponível em: http://74.125.47.132/search?q=cache:mn3hTQwu0QMJ:aof.revues.org/index2992.html $+\% 221 \mathrm{a}+$ construction $+\mathrm{de}+\mathrm{la}+$ nation $+\mathrm{et}+\mathrm{d} \% \mathrm{E} 2 \% 80 \% 99 \mathrm{un}+\bmod \% \mathrm{C} 3 \% \mathrm{~A} 8 \mathrm{le}+$ culinaire + national $\% 22 \& \mathrm{~cd}=1 \& \mathrm{hl}=\mathrm{pt}-\mathrm{BR} \& \mathrm{ct}=\mathrm{clnk} \& \mathrm{gl}=\mathrm{br}$. Acesso em: 20 jun. 2009.

BERTRAN, Miriam. Cambio alimentario e identidad de los indígenas mexicanos. México: UNAM, 2005.

(1979), Grenand (1996), Van Velthem (1996), Murrieta (2001), Erikson (2006). 
ESTHER KATZ - Alimentação indígena na América Latina ...

BUCHILLET, Dominique. Interpretação da doença e simbolismo ecológico entre os índios Desana. Boletim do Museu Paraense Emílio Goeldi: Série Antropologia, Belém, v. 4, n. 1, p. 27-42, 1988.

CASAS, Alejandro et al. Las plantas en la alimentación mixteca: una aproximación etnobótanica, América Indígena, México, v. 47, n. 2, p. 317-343, 1987.

CABAlZAR, Aloisio; RICARDO, Carlos Alberto (Orgs.). Povos Indígenas do Rio Negro. São Paulo/São Gabriel da Cachoeira: Instituto Socioambiental/FOIRN, 2006.

CHERNELA, Janet. The Wanano Indians of the Brazilian Amazon: a sense of space. Austin: University of Texas Press, 1993.

DUFOUR, Darna L. Diet and nutritional status of ameridians: a review of the literature. Cadernos de Saude Publica, São Paulo, v. 7, n. 4, p. 481-502, out./dez. 1991.

ELOY Ludivine. Diversité alimentaire et urbanisation: le rôle des mobilités circulaires des amérindiens dans le Nord-Ouest amazonien. Anthropology of Food, Sallebœuf (France), n. 4, mai. 2008. Disponível em: http://aof.revues.org/index2882.html . Acesso em: 20 jun. 2009.

EMBRAPA. Mandioca, o pão do Brasil. Brasilia: EMBRAPA (Empresa Brasileira de Pesquisa Agropecuária), 2005.

EMPERAIRE, Laure et al. Diversité agricole et patrimoine dans le moyen Rio Negro (Amazonie brésilienne). Les Actes du Bureau des Ressources Génétiques, Paris, n. 7, p. 139-153, 2008.

ERIKSON, Philippe (Org.). La pirogue ivre: bières traditionnelles en Amazonie. Saint Nicholas de Port: Musée Français de la Brasserie. 2006.

GARNELO, Luiza. Cosmologia, ambiente e saúde: mitos e ritos alimentares baniwa. História, Ciências, Saúde, Rio de Janeiro, v. 14, p. 191-212, dez. 2007.

GONZÁLEZ DE LA VARA, Fernán (Org.). La cocina mexicana a través de los siglos. México: Clío/Fundación Herdez, 1996-1997.

GRENAND, Françoise. Cachiri: l'art de vivre de la bière de manioc chez les Wayãpi de Guyane. In. BATAILLE-BENGUIGUI, M. C.; COUSIN F. (Orgs.). Cuisines: reflets des sociétés. Paris: Sépia/Musée de l'Homme, 1996. p. 325-345.

HUGH-JONES, Christine. From the Milk River: spatial and temporal processes in Northwest Amazonia. Cambridge: Cambridge University Press, 1979.

INEGI. II Conteo general de población y vivienda 2005. México: INEGI (Instituto Nacional de Estadística, Geografía e Informática), 2007. Disponível em: http://www.inegi.gob.mx . Acesso em: 20 jun. 2009. 
ESTHER KATZ - Alimentação indígena na América Latina ...

KATZ, Esther. La cueillette des adventices comestibles au Mexique, Ecologie Humaine, França, v. 10, n. 1, p. 25-41, 1992.

KATZ, Esther. Tortillas, haricots et sauce piquante: l'alimentation au Mexique. In. Savoirs Partagés. Montpellier: Agropolis Muséum, 2004. Disponível em: http://museum.agropolis.fr/ . Acesso em: 20 jun. 2009.

KATZ, Esther. Les normes alimentaires des paysans mixtèques (état d'Oaxaca, Mexique). Journal des Anthropologues, Montrouge, v. 106-107, p. 205-223, 2006 a.

KATZ, Esther. Statut de la chasse et consommation du gibier chez les paysans mixtèques du Mexique. Approche diachronique. In. SIDERA, I.; VILA, E.; ERIKSON, $\mathrm{Ph}$.; (Orgs.). La chasse: pratiques sociales et symboliques. Paris: De Boccard, 2006b. p. 181-192.

KATZ, Esther. Cuisine quotidienne et cuisine festive en pays mixtèque (état d'Oaxaca, Mexique). Espaces, ustensiles et préparations culinaires à l'épreuve du changement. Cahiers de l'OCHA, Faire la cuisine, v. 11, p. 180-190, jul. 2006c.

KATZ, Esther. Émigration, mutations sociales et changements culinaires en pays mixtèque (Oaxaca, Mexique). Anthropology of Food, Sallebœuf (France), n. 4, mai. 2008. Disponível em: http://74.125.93.132/search?q=cache:FT1EwgzZnFUJ:aof.revues.org/index2912.html+ $\% 22 \% \mathrm{C} 3 \% 89$ migration, + mutations + sociales + et + changements + culinaires $\% 22 \& \mathrm{~cd}=1 \&$ $\underline{\mathrm{hl}=\mathrm{pt}-\mathrm{BR} \& \mathrm{ct}=\mathrm{clnk} \& \mathrm{gl}=\mathrm{br}}$. Acesso em: 20 jun. 2009.

LUCIANO, Gersem dos Santos. Alimentação baniwa. In. Seminário Alimentação e cultura. Brasília: CET-UnB, 2008.

MILLIKEN, William; ALBERT, Bruce; GOODWIN GOMEZ, Gale. Yanomami, a forest people. Kew: Royal Botanic Garden. 1999.

MURRIETA, Rui Sergio S. Dialética do sabor: alimentação, ecologia e vida cotidiana em comunidades ribeirinhas da Ilha de Ituqui, Baixo Amazonas, Pará. Revista de Antropologia, São Paulo, v. 44, n. 2, p. 39-88, 2001.

OLIVEIRA, Adelia E. de. São João, povoado do Rio Negro. Boletim do Museu Emilio Goeldi: Série Antropologia, Belém, n. 58, p. 1-56, 1972.

PASTOR, Rodolfo. Campesinos y reformas: La Mixteca, 1748-1856. México: Colegio de México, 1987.

PETRICH, Blanche. Niega UNESCO estatus a la cocina mexicana. La Jornada. 2005. Disponível em: http://www.jornada.unam.mx/2005/11/26/a44n1gas.php/ . Acesso em: 20 jun. 2009.

DE ROBERT, Pascale; VAN VELTHEM, Lucia. L'heure du tacacá: consommation et valorisation d'aliments traditionnels amazoniens en zone urbaine (Brésil). 
ESTHER KATZ - Alimentação indígena na América Latina ...

Anthropology of Food, Sallebœuf (France), n. 4, mai. 2008. Disponível em: http://aof.revues.org/index3533.html . Acesso em: 20 jun. 2009.

RENAULT-LESCURE Odile. La tentation monolingue: exemple d'acculturation linguistique chez les indiens multilingues d'Amazonie brésilienne. Cahiers des Sciences Humaines, v. 27, n. 3-4, p. 517-534, 1991.

REICHEL-DOLMATOFF, Gerardo. Desana: simbolismo de los Indios Tukano de Vaupés. Bogotá: Universidad de los Andes, 1968.

RIBEIRO, Berta G. Os Índios das águas pretas. São Paulo: EDUSP/Companhia das Letras, 1995.

SCHOEPF, Daniel. La marmite Wayana: cuisine et société d'une tribu d'Amazonie. Genève: Musée d'ethnographie, 1979.

VAN VELTHEM, Lucia H. Comer verdareiramente: produção e preparação de alimentos entre os wayana. Horizontes Antropológicos, Porto Alegre, v. 2, n. 4, p. 1026, jan./jun. 1996.

ZOLLA, Carlos. Elogio del dulce: ensayo sobre la dulcería mexicana. México: Fondo de Cultura Económica, 1988. 